\title{
Identification of Sources of Multiple Disease Resistance in Mini-core Collection of Chickpea
}

\author{
S. Pande, G. Krishna Kishore, H. D. Upadhyaya, and J. Narayana Rao, International Crops Research Institute for \\ the Semi-Arid Tropics (ICRISAT), Patancheru 502 324, Andhra Pradesh, India
}

\begin{abstract}
Pande, S., Kishore, G. K., Upadhyaya, H. D., and Rao, J. N. 2006. Identification of sources of multiple disease resistance in mini-core collection of chickpea. Plant Dis. 90:1214-1218.

Host plant resistance is the major component in the management of fungal diseases in chickpea (Cicer arietinum). We screened a chickpea mini-core collection composed of 211 germ plasm accessions representing the diversity of the global chickpea germ plasm collection of 16,991 , maintained at the International Crops Research Institute for the Semi-Arid Tropics to identify sources of multiple disease resistance. The accessions were screened for resistance against Ascochyta blight (Ascochyta rabiei), Botrytis gray mold (Botrytis cinerea), Fusarium wilt (Fusarium oxysporum f. sp. ciceris), and dry root rot (Rhizoctonia bataticola) under a controlled environment. High levels of resistance were observed to Fusarium wilt (FW), where 21 accessions were asymptomatic and 25 resistant. In all, 3, 55, and 6 accessions were moderately resistant to Ascochyta blight ( $\mathrm{AB})$, Botrytis gray mold (BGM), and dry root rot (DRR) respectively. ICC 11284 was the only accession moderately resistant to both AB and BGM. Combined resistance also was identified for DRR and FW in 4 accessions, and for BGM and FW in 11 accessions. Through this study, chickpea germ plasm accessions were identified that possess high levels of resistance to more than one fungal disease and would be useful in chickpea multiple disease resistance breeding programs.
\end{abstract}

Chickpea (Cicer arietinum L.) is an important pulse crop in over 45 countries of Asia, Africa, the Americas, and Oceania, with annual production of 8.62 million tons from 11.12 million hectares (4). Chickpea is used as an important source of protein in human nutrition and cattle feed, and also to improve soil fertility by biological $\mathrm{N}_{2}$ fixation (14). Additionally, chickpea is tolerant to heat and drought and also suitable for production in low-fertility soils. Chickpea cultivars are of basically two types. Kabuli chickpea, with large seeds that are shaped like an owl head and have a cream-colored seed coat, is grown in the Mediterranean regions, West Asia and North Africa (WANA), Australia, and North America. Desi chickpea, with small seed size, angular shape, and dark-colored seed coat, is grown in South Asia, Iran, Ethiopia, and Mexico. Additionally, intermediate chickpea, a third type, with pea-shaped seeds, also was observed (37). The average global productivity of chickpea is about $0.8 \mathrm{t} \mathrm{ha}^{-1}$, which is far below the actual yield potential, because the crop is subjected to a number of fungal diseases throughout the growing season $(7,27)$.

Corresponding author: S. Pande

E-mail: s.pande@cgiar.org

Accepted for publication 12 May 2006.

DOI: 10.1094/PD-90-1214

(C) 2006 The American Phytopathological Society
Foliar diseases Ascochyta blight (AB), caused by Ascochyta rabiei (Pass.) Labr. (teleomorph, Didymella rabiei (Kov.) v. Arx.), and Botrytis gray mold (BGM), caused by Botrytis cinerea Pers. ex. Fr. (teleomorph, Botryotinia fuckeliana (de Bary) Whetzel), are widely distributed and can cause complete crop failure $(3,24)$. Among the soilborne diseases, Fusarium wilt (FW), caused by Fusarium oxysporum Schlechtend. emend W. C. Snyder. \& H. N. Hans. f. sp. ciceris (Padwick) W. C. Snyder \& H. N. Hans. (13), and dry root rot (DRR), caused by Rhizoctonia bataticola (Taub.) Butler, are widely distributed in the semi-arid tropics, resulting in considerable yield losses $(17,21)$. Deployment of host plant resistance (HPR) is the best option for managing these four fungal diseases because it is cost effective. Because of the complex association of fungal diseases of chickpea, successful production of chickpea often requires cultivars resistant to multiple diseases (19). There are several sources of strong resistance to FW (9), but only a moderate level of resistance has been identified for $\mathrm{AB}$ and $\mathrm{BGM}$ $(3,24,25)$. As a result, the search continues for sources of higher levels of HPR.

To overcome the need for large-scale evaluation of germ plasm collections against various biotic and abiotic stresses, Frankel (5) proposed the concept of core collection (10\% of entire collection) to minimize repetitiveness within the collection and to represent the genetic diversity of a crop species. Following the methods described by Frankel and Brown (6) and Brown (2), Upadhyaya et al. (35) developed a chickpea core collection consisting of 1,956 accessions, which represented the global chickpea germ plasm collection at the International Crops Research Institute for the Semi-Arid Tropics (ICRISAT). When the number of accessions in a core collection is large, such as with chickpea, their systematic evaluation would require large resources; therefore, Upadhyaya and Ortiz (36) suggested a mini-core (10\% of core collection, $1 \%$ of entire collection) approach. A chickpea mini-core consisting of 211 accessions, representing genetic diversity of the core collection and entire collection, was developed at ICRISAT (36) for use by crop improvement scientists. The main objective of this study was to identify sources of multiple disease resistance in the mini-core subset of the chickpea germ plasm against important fungal pathogens for use in disease resistance breeding programs to develop broad-based, disease-resistant cultivars.

\section{MATERIALS AND METHODS}

This study was conducted during June to November 2004 under controlled environment conditions at ICRISAT, Patancheru, India.

Seed source. Seed of 211 accessions of the chickpea mini-core subset, comprising 159 Desi, 44 Kabuli, and 8 intermediatetype seed, were used in this study. Seed of the mini-core collection were obtained from the Genetic Resources Division, ICRISAT, Patancheru, India. Seed of all the accessions used as susceptible checks for different diseases were obtained from the Department of Pathology, ICRISAT.

Fungal pathogens. Pure culture of race 1 of $F$. oxysporum f. sp. ciceris (8) that was maintained at $5^{\circ} \mathrm{C}$ in the laboratory of ICRISAT was used for evaluation for FW resistance. Pure cultures of $R$. bataticola (ICRISAT isolate) from ICRISAT, Patancheru, A. rabiei (pathotype AB 6) from Hisar (1), and B. cinerea (Pantnagar isolate) from Pantnagar, India, were isolated from diseased chickpea plants collected from disease nurseries. Isolations were made separately from diseased plants on potato dextrose agar medium and the cultures were purified by obtaining single-spore isolates for each pathogen by using standard mycological techniques. Virulence of these single-spore isolates was confirmed on susceptible 
cultivars before being used for resistance evaluation.

Evaluation for AB resistance. Inoculum preparation. Chickpea seed of Kabuli genotype ICCV 88901 (50 $\mathrm{g}$ of seed in a 250-ml conical flask) were soaked overnight in water, autoclaved at $121^{\circ} \mathrm{C}$ for 25 $\mathrm{min}$, and inoculated with a 1-cm-diameter disc of actively growing culture of $A$. $r a-$ biei. Inoculated seeds were incubated at $20^{\circ} \mathrm{C}$ for 8 days with a 12 -h photoperiod. Seeds with profuse sporulation were stirred in sterile distilled water (SDW) to facilitate the release of conidia into water and filtered through a muslin cloth (26). The conidial concentration in the suspension was adjusted to $5 \times 10^{4}$ spores $\mathrm{ml}^{-1}$ and used as inoculum.

Inoculation and disease scoring. Seedlings of the mini-core accessions along with a susceptible check Pb 7 (ICC 4991) were raised in 40-by-30-by-5-cm plastic trays filled with sand and vermiculite mixture $(10: 1)$ in a greenhouse, maintained at $25 \pm 3^{\circ} \mathrm{C}$ and a $12-\mathrm{h}$ photoperiod. Twelveday-old seedlings were transferred to a growth room maintained at $20 \pm 1^{\circ} \mathrm{C}$ with approximately 1,500 lux light intensity for $12 \mathrm{~h}$ a day. The seedlings were inoculated artificially by spraying the inoculum on the foliage using a hand-operated atomizer. Inoculated plants were allowed to partially dry for $30 \mathrm{~min}$ to avoid dislodging of the spores and, thereafter, $100 \%$ relative humidity $(\mathrm{RH})$ was provided $24 \mathrm{~h}$ a day up to 4 days after inoculation (DAI) and thereafter 6 to $8 \mathrm{~h}$ a day up to 10 DAI (10). Disease severity of individual accession was measured 10 DAI on a 1 -to-9 rating scale $(1=$ healthy plants and $9=$ completely killed plants; 20). The design of the experiment followed a randomized complete block design (RCBD) with three replications with eight seedlings in each replication and repeated once.

Evaluation for BGM resistance. Inoculum preparation. Matured flowers of Tagetus erecta L. (marigold) were dried in shade and the petals were separated. The dried petals were soaked in SDW for 30 min and filled up to one-fifth volume in $250-\mathrm{ml}$ conical flasks. A $1 \%$ sucrose solution $(2 \mathrm{ml})$ was added to each flask and autoclaved at $121^{\circ} \mathrm{C}$ for $25 \mathrm{~min}$. Each flask was inoculated with a $1-\mathrm{cm}$ disc of actively growing $B$. cinerea colony and incubated for 8 days at $25^{\circ} \mathrm{C}$ and a 12 -h photoperiod. The profusely sporulating culture on petals was suspended in SDW and filtered through cheesecloth. Concentration of conidia in the filtrate was adjusted to $3 \times$ $10^{5} \mathrm{ml}^{-1}$ and used as inoculum.

Inoculation and disease scoring. Seedlings of the test accessions along with susceptible check JG 62 were raised in plastic trays filled with sand and vermiculite mixture (10:1) under greenhouse conditions, as described above. Ten-day-old seedlings were transferred to a growth room maintained at $15 \pm 2^{\circ} \mathrm{C}$ with ap- proximately 1,500 lux light intensity for 12 $\mathrm{h}$ a day (22). Test seedlings were inoculated by foliar spray of the inoculum using a hand-operated atomizer. Following a partial drying of the inoculum for $30 \mathrm{~min}$, $100 \% \mathrm{RH}$ was maintained $24 \mathrm{~h}$ a day for 10 DAI and, thereafter, $8 \mathrm{~h}$ a day for another 10 days. Disease severity was recorded 20 DAI on a 1-to-9 rating scale $(1=$ healthy plants and $9=$ completely killed plants; 32). The experiment was conducted in triplicate using RCBD design with eight seedlings in each replication, and repeated twice.

Evaluation for FW resistance. Inoculum preparation. A 7-mm disc of actively growing $F$. oxysporum culture was put into a $250-\mathrm{ml}$ conical flask containing $100 \mathrm{ml}$ of sterilized potato dextrose broth and incubated for 5 days at $25^{\circ} \mathrm{C}$ and $125 \mathrm{rpm}$. The culture then was homogenized in SDW and adjusted to $5 \times 10^{5}$ conidia $\mathrm{ml}^{-1}$ for use as inoculum.

Inoculation and disease scoring. Chickpea mini-core subset was evaluated for FW resistance using a root-dip inoculation technique (20). Eight-day-old seedlings of each accession, along with susceptible check JG 62, grown in sterile sand were uprooted and root inoculated by dipping in the inoculum for $30 \mathrm{~s}$ to enable conidia to adhere to the roots. Inoculated seedlings were transplanted in pre-irrigated sterile vertisol and sand (3:1) and incubated in a greenhouse at $25 \pm 3^{\circ} \mathrm{C}$. Inoculated seedlings were observed for wilt symptoms from 15 to 30 DAI at a 5-day interval. Fifteen seedlings of each accession were tested in three replications in RCBD design and the experiment was conducted twice.

Evaluation for DRR resistance. Inoculum preparation. A 7-mm agar disc of actively growing $R$. bataticola culture was put into each 250-ml conical flask containing $100 \mathrm{ml}$ of sterilized potato dextrose broth and incubated for 5 days at $28^{\circ} \mathrm{C}$ in a stationary condition. Fungal mat from two flasks was macerated in $100 \mathrm{ml}$ of SDW, then used as inoculum.

Inoculation and disease scoring. Chickpea mini-core subset was evaluated for DRR resistance using a blotter paper technique $(20,23)$. Seven-day-old seedlings of individual accessions, along with susceptible check ICC 11324, grown in sterilized sand were uprooted and root inoculated by dipping in the inoculum for $1 \mathrm{~min}$. Inoculated seedlings were placed in folded, moist blotting paper with the shoots left outside, then incubated at $35^{\circ} \mathrm{C}$ with a $12-\mathrm{h}$ photoperiod. Disease severity was recorded 6 DAI on a 1-to-9 rating scale $(1=$ no infection on roots and $9=$ roots infected and completely discolored; 20). Five seedlings of each accession were tested using three replications in RCBD design. The experiment was conducted twice.

Seed mass. Seed $(n=100)$ were taken randomly from a fully dried $(<10 \%$ moisture) and cleaned seed lot of an individual chickpea accession and weighed to calculate100-seed mass.

Disease reaction. Reaction of individual accessions to $\mathrm{AB}, \mathrm{BGM}$, and DRR was categorized as asymptomatic (disease score 1.0 on a 1-to-9 rating scale), resistant (disease score 1.1 to 3.0 ), moderately resistant (disease score 3.1 to 5.0), susceptible (disease score 5.1 to 7.0), and highly susceptible (7.1 to 9.0). Reaction of minicore accessions to $\mathrm{FW}$ was categorized as asymptomatic ( $0 \%$ mortality), resistant (1 to $10 \%$ mortality), moderately resistant (11 to $20 \%$ mortality), susceptible (21 to $50 \%$ mortality), and highly susceptible (51 to $100 \%$ mortality).

\section{RESULTS}

Among the mini-core accessions, a high level of resistance was observed for FW and a moderate level of resistance for $\mathrm{AB}$, BGM, and DRR (Table 1). Accessions were categorized and grouped based on their reaction to each disease in both tests.

Evaluation for AB resistance. Susceptible check Pb 7 (ICC 4991) had a disease rating of 9 on a 1-to- 9 rating scale at 10 DAI. Among the mini-core accessions, high levels of resistance were not found to AB. However, $1 \%$ of accessions were identified as moderately resistant (3.1 to 5 rating) to $\mathrm{AB}$ (Table 2). Among the other accessions, $19 \%$ were susceptible (5.1 to 7 rating) and $80 \%$ were highly susceptible (7.1 to 9 rating) to $\mathrm{AB}$. All three moderately resistant accessions were of the Desi type. Among these three, ICC 6306 had a

Table 1. Disease reaction of chickpea mini-core accessions against economically important foliar and soilborne fungal diseases under a controlled environment ${ }^{\mathrm{a}}$

\begin{tabular}{|c|c|c|c|c|c|}
\hline Disease & Asymptomatic & Resistant & $\begin{array}{l}\text { Moderately } \\
\text { resistant }\end{array}$ & Susceptible & $\begin{array}{c}\text { Highly } \\
\text { susceptible }\end{array}$ \\
\hline Ascochyta blight ${ }^{\mathrm{b}}$ & 0 & 0 & 3 & 40 & 168 \\
\hline Botrytis gray mold ${ }^{b}$ & 0 & 0 & 55 & 137 & 19 \\
\hline Dry root $\operatorname{rot}^{\mathrm{b}}$ & 0 & 0 & 6 & 79 & 126 \\
\hline Fusarium wilt ${ }^{\mathrm{c}}$ & 21 & 25 & 21 & 49 & 95 \\
\hline
\end{tabular}

${ }^{a}$ Reaction of mini-core accessions to individual disease is based on the mean of three replications in two sets of experiments.

${ }^{\mathrm{b}}$ Asymptomatic $=$ disease score 1.0 on a 1 -to- 9 rating scale, resistant $=$ disease score 1.1 to 3.0 , moderately resistant $=3.1$ to 5.0 , susceptible $=5.1$ to 7.0 , and highly susceptible $=7.1$ to 9.0 .

${ }^{\mathrm{c}}$ Asymptomatic $=0 \%$ mortality, resistant $=1$ to $10 \%$ mortality, moderately resistant $=11$ to $20 \%$ mortality, susceptible $=21$ to $50 \%$ mortality, and highly susceptible $=>50 \%$ mortality . 
100 -seed mass of $25 \mathrm{~g}$ whereas the rest had $<20$ g.

Evaluation for BGM resistance. Severity of BGM was very high (rating of 9 on 1-to-9 scale) in susceptible JG 62 at 20 DAI. Highly resistant accessions were not detected in the 211 members of the minicore subset. However, $26 \%$ of the accessions had a moderately resistant (3.1 to 5 rating) reaction (Table 2). About $65 \%$ of the accessions were found to be susceptible (5.1 to 7 rating) and the remaining 9\% were highly susceptible (7.1 to 9 rating) to BGM. Of the moderately resistant accessions, 33 were Kabuli type, 17 were Desi, and the remaining 5 accessions were intermediate type. Of the moderately resistant Kabuli accessions, ICC 14199 and ICC 8151 were large seeded with a 100seed mass of 58.1 and $57.6 \mathrm{~g}$, respectively. Of the promising Desi types, one accession, ICC 13124, had a 100-seed mass of $35.4 \mathrm{~g}$, which was the highest among Desi types in the mini-core subset.

Evaluation for FW resistance. Incidence of FW in susceptible check JG 62 was $100 \%$ at $25 \mathrm{DAI}$, indicating that the screening was reliable. Of the 211 minicore accessions evaluated, high levels of resistance were observed for FW. About $10 \%$ of the accessions were found to be asymptomatic and $12 \%$ were identified as resistant $(<10 \%$ mortality) to $\mathrm{FW}$ infection (Table 2). Although $10 \%$ of the accessions were found to be moderately resistant (11 to $20 \%$ ), $23 \%$ were susceptible (21 to $50 \%$ ) and $45 \%$ were highly susceptible $(>50 \%)$ to $\mathrm{FW}$. Of the asymptomatic accessions, one accession, ICC 8058, was the Kabuli type with a 100 -seed mass of 33.8 g. Within the resistant group, two accessions, ICC 13816 and ICC 13441, were the
Kabuli type with a 100-seed mass of 29 and $16.7 \mathrm{~g}$, respectively.

Evaluation for DRR resistance. Susceptible check ICC 11324 was found to be highly susceptible and had a rating of 9 on a 1 -to- 9 rating scale at 6 DAI. Of the 211 accessions evaluated for DRR, only $3 \%$ were found to be moderately resistant (3.1 to 5 rating on a 1 -to-9 rating scale) to DRR (Table 2). Furthermore, $37 \%$ of the accessions were susceptible and $60 \%$ were highly susceptible. Of the promising accessions, two (ICC 1710 and ICC 2242) were of the Desi type while four were of the Kabuli type. Of the Kabuli accessions, ICC 11764 and ICC 12328 had a 100-seed mass of 28.8 and $27.5 \mathrm{~g}$, respectively.

Multiple disease resistance. Among the mini-core accessions, no line was found resistant or moderately resistant to more than two diseases in both tests. Only one accession of the Desi type (ICC 11284) had moderate levels of resistance to both foliar diseases, AB and BGM. Combined resistance to $\mathrm{AB}$ and soilborne diseases was not observed in any of the minicore accessions tested. Two accessions (ICC 11764 and ICC 12328) had a combined resistance to both BGM and DRR. Combined resistance to BGM and FW was found in 11 accessions. Four accessions had a combined resistance to both FW and DRR (Table 3).

The 18 accessions that had a combined resistance to two fungal diseases originated from Afghanistan, Bangladesh, Chile, Cyprus, India, Iran, Mexico, and Russia and the Commonwealth of Independent States (CIS). Among these accessions, 12 were Desi, 5 were Kabuli, and one was of intermediate type (Table 3).

\section{DISCUSSION}

Due to limited availability of resources for present-day agricultural research, extensive evaluations of an entire germ plasm for a particular characteristic is difficult and also time consuming. Thus, the concept of core collections that represent a large number of accessions in a germ plasm has been put forward to represent the diversity of an entire germ plasm (5). Core subsets that maintain the variation present in the germ plasm with fewer accessions provide an easy approach to accessing genetic resources. The chickpea mini-core collection, with 211 accessions (1.24\% of entire collection), represents the total diversity contained in the entire collection (36). This mini-core subset drastically reduces the number of entries to be evaluated and provides a working collection of chickpea germ plasm that can be extensively examined for economically important biotic and abiotic stresses $(15,29)$.

Breeding for $\mathrm{AB}$ and $\mathrm{FW}$ are among the important breeding goals in chickpea across the world (30) and for BGM in south Asia $(18,25)$. Sources for FW resistance were identified (9), but breeding programs of $\mathrm{AB}$ and $\mathrm{BGM}$ often are limited by the absence of high levels of resistance in chickpea germ plasm. A few resistant sources for $\mathrm{AB}$ and $\mathrm{BGM}$ have been identified through field evaluation; however, their resistance is location specific due to variability in the pathogens $(24,25)$. Reaction of ICC 13816 to AB was found to be resistant in several countries (31), but its reaction in the present study was found to be susceptible. Iqbal et al. (12) also observed a similar susceptible reaction in this accession. Moreover, concerted efforts

Table 2. Details of selected accessions showing resistance to individual fungal disease identified from the chickpea mini-core collection ${ }^{\mathrm{a}}$

\begin{tabular}{|c|c|c|c|}
\hline \multirow[b]{2}{*}{ Target disease } & \multicolumn{3}{|c|}{ Disease reaction } \\
\hline & Asymptomatic & Resistant & Moderately resistant \\
\hline Ascochyta blight ${ }^{\mathrm{b}}$ & $\ldots$ & $\ldots$ & ICCs 1915,6306 and 11284 \\
\hline Botrytis gray mold ${ }^{b}$ & $\cdots$ & $\cdots$ & $\begin{array}{l}\text { ICCs } 1180,2990,4533,4841,4872,6263, \\
6279,6877,7255,7323,7308,7315,7554, \\
7571,7668,7819,8151,8261,8318,8740, \\
8855,9137,9402,9848,9862,10341, \\
10755,10885,11284,11764,11879, \\
12028,12037,12155,12328,12492, \\
13124,13187,13219,13283,13357, \\
13461,13599,13628,13816,14199, \\
14595,15264,15294,15333,15406, \\
15435,15697,15802, \text { and } 16796\end{array}$ \\
\hline Dry root rot $^{\mathrm{b}}$ & $\cdots$ & $\ldots$ & $\begin{array}{l}\text { ICCs } 1710,2242,2277,11764,12328 \text {, and } \\
13441\end{array}$ \\
\hline Fusarium wilt ${ }^{\mathrm{c}}$ & $\begin{array}{l}\text { ICCs } 637,1205,1356,1392,2065, \\
2072,2629,2990,3218,4495,4533, \\
5639,6279,7184,8058,13219,14402, \\
14669,16207,16374 \text {, and } 16903\end{array}$ & $\begin{array}{l}\text { ICCs } 67,95,791,867,1164,1398,2210, \\
3230,6571,6811,6816,6874,7554, \\
7819,9848,11584,11664,12028, \\
12155,13441,13599,13816,14815, \\
14831, \text { and } 15868\end{array}$ & $\begin{array}{l}\text { ICCs } 1397,1431,1510,1715,1923,3325, \\
4593,5135,5845,7867,8950,9002, \\
10393,12307,12916,12928,12947 \\
15567,15606,15610, \text { and } 16487\end{array}$ \\
\hline
\end{tabular}

\footnotetext{
a Reaction of mini-core accessions to individual disease is based on the mean of three replications in two sets of experiments, and accessions with resistance to more than one disease are not mentioned in the table.

${ }^{\mathrm{b}}$ Asymptomatic $=$ disease score 1.0 on a 1 -to- 9 rating scale, resistant $=$ disease score 1.1 to 3.0 , moderately resistant $=3.1$ to 5.0, susceptible $=5.1$ to 7.0 , and highly susceptible $=7.1$ to 9.0 .

c Asymptomatic $=0 \%$ mortality, resistant $=1$ to $10 \%$ mortality, moderately resistant $=11$ to $20 \%$ mortality, susceptible $=21$ to $50 \%$ mortality, and highly susceptible $=>50 \%$ mortality.
} 
never were made to identify multipledisease-resistance in chickpea germ plasm accessions. In this study, use of the chickpea mini-core collection confirmed the presence of high to moderate levels of resistance in germ plasm against these three fungal diseases of economic concern.

Only a small fraction $(<10 \%)$ of the chickpea germ plasm had been evaluated for resistance to BGM prior to this study (35). A large portion of the Kabuli chickpea germ plasm has been evaluated for $A B$ resistance under field conditions $(30,31)$; however, controlled environment screening is needed for confirmation of field resistance. Few specific attempts have been made to identify DRR resistance in chickpea germ plasm $(22,28)$. To know the complete range of tolerance levels available in cultivated chickpea, it becomes necessary to evaluate the whole range of the germ plasm collection. Studies such as the present one help identify resistant sources by specific evaluation of the germ plasm accessions belonging to different clusters represented by selected mini-core accessions, thereby avoiding extensive germ plasm screening. By comparing late leaf spot disease resistance in peanut germ plasm and a core collection, Holbrook and Anderson (11) observed that the success rate when screening within clusters found to contain resistant lines was greater $(P \leq$ $0.01)$ than the success rate for lines not in those clusters. Similarly, a subsample of the core collection of common bean was useful for identifying ranges of accessions within the active Phaseolus spp. collection that possessed a high incidence of putative physiological resistance to white mold (16). Upadhyaya (33) identified 18 peanut lines having drought resistance-related traits, and specific leaf area and soil plant analysis development chlorophyll meter reading similar to or better than the control cultivars in the peanut mini-core (34).

Use of host resistance to manage biotic constraints is crucial to reduce management costs and increase profitability of chickpea cultivation, because a large acreage of chickpea is grown in developing countries. The information generated in this study will be of great value to plant breeders in their effort to identify sources of resistance to fungal diseases of chickpea. This mini-core collection can be used very effectively as a starting point for research involving screening of the germ plasm collection for sources of desirable traits in chickpea. The information on clusters to which particular accessions with traits of interest belong will assist in looking extensively for more accessions with similar traits in the larger subsets, core collection, and, eventually, the entire collection. For example, the mini-core accession ICC 11284, a Desi accession from Russia and the CIS that was tolerant to both $\mathrm{AB}$ and BGM, was selected from cluster 27 to represent four accessions (ICC 11284, ICC 11764, ICC 12328, and ICC 13219) of the core collection. Furthermore, these four accessions represent four clusters of the entire collection: cluster 12 (6 accessions), cluster 32 (41 accessions), cluster 84 (48 accessions), and cluster 28 (49 accessions). It would be useful to evaluate 3 accessions of the core and 140 accessions of the entire collection for resistance to $\mathrm{AB}$ and $\mathrm{BGM}$ diseases. Identification of mini-core accessions with resistance against a select combination of two diseases (BGM and FW, BGM and DRR, and FW and DRR) also would permit use of diverse sources for future breeding efforts and ensure a better chance of success in improving the disease resistance of chickpea.

\section{LITERATURE CITED}

1. Basandrai, A. K., Pande, S., Krishna Kishore, G., Crouch, J. H., and Basandrai, D. 2005. Cultural, morphological and pathological variation in Indian Isolates of Ascochyta rabiei, the chickpea blight pathogen. Plant Pathol. J. 21 (3):1-5.

2. Brown, A. H. D. 1989. Core collections: a practical approach to genetic resources management. Genome 31:818-824.

3. Davidson, J. A., Pande, S., Bretag, T. W., Lindbeck, K. D., and Kishore, G. K. 2004. Biology and management of Botrytis spp. in legume crops. Pages 295-318 in: Botrytis: Biology, Pathology and Control. Y. Elad, B Williamson, P. Tudzynski, and N. Delen, eds. Kluwer Academic Publishers, Dordrecht, The Netherlands.

4. FAO Bulletin of Statistics. 2005. Food and Agriculture Organization of the United $\mathrm{Na}-$ tions, Rome.

5. Frankel, O. H. 1984. Genetic perspectives of germplasm conservation. Pages 161-170 in: Genetic Manipulation: Impact on Man and Society. W. K. Arber, ed. Cambridge University Press, Cambridge.

6. Frankel, O. H., and Brown, A. H. D. 1984 Plant genetic resources today: a critical appraisal. Pages 249-268 in: Crop Genetic Resources: Conservation and Evaluation. J. H. W. Holden and J. T. Williams, eds. Allen and Unwin, Winchester, MA

7. Haware, M. P., Jimenez-Diaz. R. M., Amin. K. S., Phillips. J. C., and Halila. H. 1990. Integrated management of wilt and root rots of chickpea. Pages 129-137 in: Chickpea in the Nineties: Proc. Second Int. Workshop Chickpea Improvement. International Crops Research Institute for the Semi-Arid Tropics, Patancheru, AP, India.

8. Haware, M. P., and Nene, Y. L. 1982. Races of

Table 3. Details of selected accessions showing combined resistance to different fungal diseases identified form the chickpea mini-core collection ${ }^{\mathrm{a}}$

\begin{tabular}{|c|c|c|c|c|c|}
\hline \multirow[b]{2}{*}{ ICC number } & \multicolumn{3}{|c|}{ Disease reaction $^{b}$} & \multirow[b]{2}{*}{ Alternate identity } & \multirow[b]{2}{*}{ Seed type } \\
\hline & Origin ${ }^{c}$ & Resistant & Moderately resistant & & \\
\hline 1710 & India & $\ldots$ & DRR, FW & P $1415 ; 6237$ & Desi \\
\hline 2242 & India & $\ldots$ & DRR, FW & P $1815 ; 1478$ Xxi & Desi \\
\hline 2277 & Iran & $\ldots$ & DRR, FW & P $1883-1$ & Kabuli \\
\hline 2990 & Iran & $\mathrm{FW}^{\mathrm{d}}$ & BGM & P $3454 ; 15871627$ & Desi \\
\hline 4533 & India & $\mathrm{FW}^{\mathrm{d}}$ & BGM & P 6080; PLGR No. 41 & Desi \\
\hline 6279 & India & $\mathrm{FW}^{\mathrm{d}}$ & BGM & NEC 167; PI 212893 & Desi \\
\hline 7554 & Iran & FW & BGM & P 3239; 13841412 & Desi \\
\hline 7819 & Iran & FW & BGM & NEC 1750; P 3249 & Desi \\
\hline 9848 & Afghanistan & FW & BGM & NEC 2687-2; 755C 2 & Intermediate \\
\hline 11284 & Russia and CIS & $\ldots$ & $\mathrm{AB}, \mathrm{BGM}$ & WIR 1735 & Desi \\
\hline 11764 & Chile & $\ldots$ & BGM, DRR & INIA 45 & Kabuli \\
\hline 12028 & Mexico & FW & BGM & 74TA 1740 & Desi \\
\hline 12155 & Bangladesh & FW & BGM & JM 3787 & Desi \\
\hline 12328 & Cyprus & $\ldots$ & BGM, DRR & Cyprus local & Kabuli \\
\hline 13219 & Iran & $\mathrm{FW}^{\mathrm{d}}$ & BGM & P 3046; PI 450953; Ardabil 169 & Desi \\
\hline 13441 & Iran & FW & DRR & P 4026; PI 451305 & Kabuli \\
\hline 13599 & Iran & FW & BGM & P 6322; PI 360583 & Desi \\
\hline 13816 & Russia and CIS & FW & BGM & NEC 141; ILC 3279 & Kabuli \\
\hline
\end{tabular}

a Reaction of mini-core accessions to individual disease is based on the mean of three replications in two sets of experiments.

b Disease severity of Ascochyta blight (AB), Botrytis gray mold (BGM), and dry root rot (DRR) was measured on a 1-to-9 rating scale. Accessions with mean disease severity of 1 were considered to be asymptomatic, 1.1 to 3 resistant, and 3.1 to 5 moderately resistant. Severity of Fusarium wilt (FW) was measured as percent mortality 30 days after inoculation. Accessions with no mortality were considered to be asymptomatic, 1 to $10 \%$ mortality resistant, and 11 to $20 \%$ mortality moderately resistant.

${ }^{\mathrm{c}} \mathrm{CIS}=$ the Commonwealth of Independent States.

d Asymptomatic to Fusarium wilt. 
Fusarium oxysporum f. sp. ciceris. Plant Dis. 66:809-810.

9. Haware, M. P., Nene, Y. L., Pundir, R. P. S., and Rao, J. N. 1992. Screening of world chickpea germplasm for resistance to Fusarium wilt. Field Crops Res. 30:147-154.

10. Haware, M. P., van Rheenen H. A., and Prasad, N. S. S. 1995. Screening for Ascochyta blight resistance in chickpea under controlled environment and field conditions. Plant Dis. 79:132-135.

11. Holbrook, C. C., and Anderson, W. F. 1995. Evaluation of a core collection to identify resistance to late leafspot in peanut. Crop Sci. 35:1700-1702.

12. Iqbal, S. M., Bakhash, A., Malik, S. R., and Haqqani, A. M. 2005. Screening of chickpea lines for resistance to Ascochyta blight. Int. Chickpea and Pigeonpea Newsl. 12:34-35.

13. Jalali, B. L., and Chand, H. 1992. Chickpea wilt. Pages 429-444 in: Plant Diseases of International Importance. Vol. 1. Diseases of Cereals and Pulses. U. S. Singh, A. N. Mukhopadhayay, J. Kumar, and H. S. Chaube, eds. Prentice Hall, Englewood Cliffs, NY.

14. Jodha, N. S., and Rao, K. V. S. 1987. Chickpea: world importance and distribution. Pages 1-10 in: The Chickpea. M. C. Saxena and K. B. Singh, eds. CAB International, London.

15. Krishnamurthy, L., Kashiwagi, J., Upadhyaya, H. D., and Serraj, R. 2003. Genetic diversity of drought-avoidance root traits in the mini-core germplasm collection of chickpea. Int. Chickpea and Pigeonpea Newsl. 10:21-24.

16. Miklas, P. N., Delorme, R., Hannan, R., and Dickson, M. H. 1999. Using a sub-sample of the core collection to identify new sources of resistance to white mold in common bean. Crop Sci. 39:569-573.

17. Mohammad, Q. A. A. 1986. Losses in yield due to Rhizoctonia root rot of chickpea in Bihar. Indian Phytopathol. 39:590-592.

18. Muehlbauer, F. J., and Kaiser, W. J. 1993. Using host plant resistance to manage biotic stresses in cool season food legumes.
Euphytica 73:1-10.

19. Nene, Y. L. 1988. Multiple-disease resistance in grain legumes. Annu. Rev. Phytopathol. 26:203-217.

20. Nene, Y. L., Haware, M. P., and Reddy, M. V. 1981. Chickpea diseases: Resistance-screening techniques. Information bulletin no. 10. International Crops Research Institute for the SemiArid Tropics, Patancheru 502 324, AP, India.

21. Nene, Y. L., and Reddy, M. V. 1987. Chickpea diseases and their control. Pages 233-270 in: The Chickpea. M. C. Saxena and K. B. Singh, eds. CAB International: London.

22. Pande, S., Kishore, G. K., Ramsay, G., Williamson, B., Senthil, G., Shivram, L. P, Mallikarjuna, N., Gaur, P. M., and Rao, J. N. 2004. Biology and epidemiology of Botrytis grey mould of chickpea. Page 10 in: Proc. XIII Int. Botrytis Symp. Antalya, Turkey.

23. Pande, S., Kishore, G. K., and Rao, J. N. 2004. Evaluation of chickpea lines for resistance to dry root rot caused by Rhizoctonia bataticola. Int. Chickpea and Pigeonpea Newsl. 11:37-38.

24. Pande, S., Siddique, K. H. M., Kishore, G. K., Baaya, B., Gaur, P. M., Gowda, C. L. L., Bretag, T., and Crouch, J. H. 2005. Ascochyta blight of chickpea (Cicer arietinum): review of Biology, pathogenicity and disease management. Aust. J. Agric. Res. 56:317-332.

25. Pande, S., Singh, G., Rao, J. N., Bakr, M. A., Chaurasia, P. C. P., Joshi, S., Johansen, C., Singh, S. D., Kumar, J., Rahman, M. M., and Gowda, C. L. L. 2002. Integrated management of botrytis gray mold of chickpea. Information bulletin no. 61. International Crops Research Institute for the Semi-Arid Tropics, Patancheru 502 324, AP, India.

26. Rao, J. N., and Haware, M. P. 1991. An improved growth medium for the multiplication of Ascochyta rabiei in the laboratory. Int. Chickpea and Pigeonpea Newsl. 21:24.

27. Reddy, M. V., Nene, Y. L., Singh, G., and Bashir, M. 1990. Strategies for management of foliar diseases of chickpea. Pages 117-127 in: Chickpea in the Nineties: Proc. Second Int.
Workshop Chickpea Improvement. International Crops Research Institute for the SemiArid Tropics, Patancheru, 502 324, AP, India.

28. Salem, D. E., Omar, S. A. M., and Khattab, A. M. 1991. Screening for resistance to rootrot/wilt disease complex in chickpea. Egyptian J. Agric. Res. 69:581-593.

29. Serraj, R., Krishnamurthy, L., and Upadhyaya, H. D. 2004. Screening chickpea mini-core germplasm for tolerance to soil salinity. Int Chickpea and Pigeonpea Newsl.11:29-32.

30. Singh, K. B., Malhotra, R. S., Halila, M. H., Knights, E. J., and Verma, M. M. 1994. Current status and future strategy in breeding chickpea for resistance to biotic and abiotic stresses. Euphytica 73:137-149.

31. Singh, K. B., Reddy, M. V., and Nene, Y. L. 1984. International testing of chickpeas for resistance to Ascochyta blight. Plant Dis. 68:782-784.

32. Tripathi, H. S., and Rathi, Y. P. S. 2000. Resistance to BGM in chickpea: Screening techniques and identification of resistant sources. $\mathrm{J}$. Mycol. Plant Pathol. 30 (2):231-232.

33. Upadhyaya, H. D. 2005. Variability for drought resistance related traits in the mini-core collection of peanut. Crop Sci. 45:1432-1440.

34. Upadhyaya, H. D., Bramel, P. J., Ortiz, R., and Singh, S. 2002. Developing a minicore of peanut for utilization of genetic resources. Crop Sci. 42:2150-2156.

35. Upadhyaya, H. D., Bramel, P. J., and Singh, S. 2001. Development of a chickpea core subset using geographic distribution and quantitative traits. Crop Sci. 41:206-210.

36. Upadhyaya, H. D., and Ortiz, R. 2001. A mini core subset for capturing diversity and promoting utilization of chickpea genetic resources in crop improvement. Theor. Appl. Genet. 102:1292-1298.

37. Upadhyaya, H. D., Ortiz, R., Bramel, P. J., and Singh, S. 2002. Phenotypic diversity for morphological and agronomic characteristics in chickpea core collection. Euphytica 123:333342 . 